\title{
Matrix Dynamics of Migration Trends of Rural-Urban Population in Ghana
}

\author{
Lewis Brew ${ }^{1, *}$, Joseph Acquah ${ }^{1}$, Francis Nyarko $^{2}$, Amidu Mohammed ${ }^{1}$ \\ ${ }^{1}$ University of Mines and Technology, Department of Mathematical Sciences, Tarkwa, Ghana \\ ${ }^{2}$ University of Mines and Technology, Human Resource Unit, Tarkwa, Ghana
}

\section{Email address:}

amolewis@yahoo.com(L.Brew), lbrew@umat.edu.gh(L. Brew), jacquah@umat.edu.gh(J.Acquah), fnyanko@umat.edu.gh (F. Nyarko), mohammedamidu@ymail.com(A. Mohammed)

${ }^{*}$ Corresponding author

\section{To cite this article:}

Lewis Brew, Joseph Acquah, Francis Nyarko, Amidu Mohammed. Matrix Dynamics of Migration Trends of Rural-Urban Population in Ghana. Science Journal of Applied Mathematics and Statistics. Vol. 6, No. 2, 2018, pp. 58-64. doi: 10.11648/j.sjams.20180602.12

Received: April 24, 2018; Accepted: May 14, 2018; Published: May 25, 2018

\begin{abstract}
This paper studies the migration trends of rural and urban populations in Ghana. The matrix method approximately determines the new population percentage values of rural and urban areas in Ghana from 2016 to 2020 . The 2015 rural and urban population values were used as initial values for the projection of the other subsequent population values. The graph matrix and clustered column chart examined the trends relationship between rural and urban populations. The emerging trends of population migration at the rural and urban areas were discussed. The method revealed the upward and downward trends of populations in urban and rural areas. The accuracy of the method is proven by comparing the estimated results from the matrix method with those obtained from the website of index mundi in the literature. On the bases of these findings, the paper recommends the steps to be taken by the government and other policy makers in Ghana to avert excessive migration flow in the urban and rural areas respectively.
\end{abstract}

Keywords: Algebraic Matrix Method, Population Migration, Rural and Urban Areas, Graph Matrix

\section{Introduction}

The alarming rate of migration flow of rural-urban areas in developing countries especially Ghana and its immense effects, both short and long term is a source of worry and calls for proper investigation and immediate action [4]. Rural-urban migration is one of the most disturbing issues in Ghana. In Ghana, more than half of the Country's population lives in towns and cities and the number is expected to increase if proper measures are not put in place [8]. Increasingly, it is becoming difficult for the urban towns to accommodate the increasing number of the people from the rural areas as a result of limited basic social amenities. But as long as people continue to leave the rural area to find better lives in the city, the urban population will continue to grow, and this has serious consequences on government policies [1]. In Ghana migration occurs mostly at the northern part of the country. Majority of the people migrate from the Northern Region, Upper-East Region, Upper West Region and other parts of the country to the southern part of the country such as Accra, Sekondi-Takoradi, Tema and Kumasi to find work to improve their standard of living [7]. This migration in the aforementioned areas occurs as a result of poverty, lack of decent housing, sanitation, health care and quality of education. Since urbanization has serious effects on governmental policies, many efforts have been made by a lot of researchers in diverse fields to study the causes and its prevention. Empirical studies have revealed that migration, changes the population of the places involved, especially, the size of the population [12]. According to [13] and [14], many migrants travel short distances and that, with increasing distance the number of migrants reduces.

The phenomenon of migration of people from rural areas to urban areas had been a source of worry in all parts of the world, particularly, in many developing countries. Many researchers are of the view that proper measures should be put in place to avert these excessive migrations, especially from the rural to urban areas $[4,11]$. Though the migration cannot completely be eliminated from the system, it can at 
best be minimized if equity prevails in the distribution of the national cake of the country [2]. According to [12], ruralurban migration occurs as a result of many economic factors such as unemployment, poverty, lack of parental care, absence of developmental programs and inadequate governmental policies to promote good economic and social development for the people in such areas. It was noted that rural-urban migration had effects not only on the immigrants, especially, those who are parents but their children that are left behind [10]. It was also concluded that rural-urban migration causes labour shortages in the rural areas which have negative influence on the agricultural sector in Ghana [15]. As a result of these observations and other existing problems, this paper seeks to examine the future population trends of rural and urban areas using the methods and principles of algebraic matrix.

\subsection{Population Distribution in Ghana}

2010 Population and Housing Census conducted in Ghana revealed that Ghana's population stands at $24,658,823$. This figure represents an increase of about 30.4 percent over the 2000 census population of $18,912,079$. Of the ten administrative regions in Ghana, the highly populous region is Ashanti Region, with a population of 4,780,280, representing 19.4 percent of the country's total population, followed by Greater Accra Region, with a population of 4,010,054 constituting 16.3 percent. The least populous regions are Upper West Region and Upper East Region with a population of 702,110 and 1,046,545 representing 2.8 percent and 4.2 percent respectively. The rest of the regions have the following percentages: Volta Region (8.6\%), Central Region (8.9\%), Brong Ahafo Region (9.4\%), Western Region (9.6\%), Northern Region (10.1\%) and Eastern Region (10.7\%) [6]. From the latest United Nation report, Ghana's Population as at 2017 was estimated around 28,615,121, which is equal to $0.38 \%$ of the total population of the world [5].

\subsection{Proportion of Rural and Urban Populations in Ghana}

In 2010, the proportion of population of rural to urban dwellers was 47.8 percent and 52.2 percent respectively, however, in the year 2000, the proportion of the population living in rural and urban areas were 49.1 percent and 50.9 percent respectively [6]. According to the population pyramid of the world, Ghana's population will hit 30.5 million by the year 2020 with about $58.9 \%$ of the population residing at the urban area [9]. This can certainly be true since migration flows increase with the development of industry, commerce and, especially, transport [3]. Indeed from 2017 data, it was found that $55.2 \%$ of Ghana's populations live in the urban areas while $44.8 \%$ were rural dwellers [5].

\section{Purpose of Study}

Ghana is one of the developing countries in Africa which is experiencing a high rate of rural-urban population migration. This is as a result of poverty, lack of parental care, absence of developmental programs, high unemployment rate and inadequate governmental policies to promote good economic and social development for the people in rural areas. Most of the rural dwellers migrate to the urban areas in search of jobs. The reduction in rural population which may cause high decline in agriculture productivity and other economic activities has necessitated for this study. Therefore, the objective of this paper is to determine the trend of rural population in Ghana from 2015-2020 in other to inform the government and other stakeholders about the need to provide proper measures to improve the living conditions in the rural areas.

\section{Methodology}

\subsection{Materials and Parameters}

The algebraic matrix method examines the dynamics of populations in rural and urban areas. The study is descriptive, since it does examine a particular situation, that is, the populations of two areas as they were. The study used 2015 urban and rural population values of Ghana [7, 8]. According to $[7,8]$, the populations at urban and rural areas in Ghana at 2015 were $14,812,854 \quad(54 \%)$ and 12,597,039 (46\%) respectively. The general birth rate $(\alpha)$ and death rate $(\phi)$ in Ghana were 30.8 births/1000 and 7.1 deaths/1000 according to [8]. This provides the percentage birth and death rates in rural area as $1.4 \%$ and $0.3 \%$ and the percentage birth and death rates in urban area also as $1.7 \%$ and $0.4 \%$ respectively. In this paper, 2015 data containing rural and urban population's values, the birth and death rates were used to illustrate the initial elements of the matrix. Studies have shown that out of $3 \%$ of the rural population that move to the urban areas in search of jobs and better living, only $1 \%$ of the urban population move to the rural areas to settle for one or two reasons [8]. Considering 2015 data, where the study assumes $n \geq 1$ such that $n=1$ represents 2016, the following information in Table 1 was used:

Table 1. 2015 population information.

\begin{tabular}{lll}
\hline Parameter & Parameter Explanation & Actual Values \\
\hline$R_{0}$ & 2015 rural population value (Initial Value) & $12,597,039$ \\
$U_{0}$ & 2015 urban population value (Initial Value) & $14,812,854$ \\
$R_{n}$ and $U_{n}$ & Rural and Urban populations values at the $n$th year & - \\
$\phi$.and $\phi_{u}$ & Death rates of rural and urban populations at the $n$th year & - \\
$\alpha_{r}$ and $\alpha_{u}$ & Birth rates of rural and urban populations at the $n$th year & - \\
\hline
\end{tabular}




\begin{tabular}{lll}
\hline Parameter & Parameter Explanation & Actual Values \\
\hline$\lambda_{r}$ & $3 \%$ population leaving the rural area in the $n$th year & - \\
$\lambda_{u}$ & $1 \%$ population leaving the urban area in the $n$th year & - \\
$R_{n-1}$ and $U_{n-1}$ & Rural and urban population values in the $(n-1)^{t h}$ years & - \\
\hline
\end{tabular}

Source: Index mundi, ghana rural population.

\subsection{General Population Equation}

The general population equation in the given area in the $n t h$ year is given by:

$$
\left(\begin{array}{l}
\text { Population } \\
\text { in the nth year }
\end{array}\right)=\left(\begin{array}{l}
\text { Population } \\
\text { in the given area }
\end{array}\right)-\left(\begin{array}{l}
\% \text { of Population } \\
\text { leaving the given area }
\end{array}\right)+\left(\begin{array}{l}
\% \text { of Population } \\
\text { Co min } g \text { from newarea }
\end{array}\right)
$$

From Table 1 the populations in the rural and urban areas in the $n t h$ year before migration

$$
\left[R_{n-1}+\alpha_{r} R_{n-1}-\phi_{r} R_{n-1}\right]=\left[1+\alpha_{r}-\phi_{r}\right] \text { of } R_{n-1}
$$

and

$$
\left[U_{n-1}+\alpha_{u} U_{n-1}-\phi_{u} U_{n-1}\right]=\left[1+\alpha_{u}-\phi_{u}\right] \text { of } U_{n-1}
$$

where $R_{n-1}$ and $U_{n-1}$ are total rural and urban populations in the $(n-1)^{\text {th }}$ year. Substituting Equations (2) and (3) in Equation (1), the new rural and urban populations after migration in the $n t h$ year are given as:

$$
\begin{aligned}
& R_{n}=R_{n-1}+\alpha_{r} R_{n-1}-\phi_{r} R_{n-1}-\lambda_{r}\left[R_{n-1}+\alpha_{r} R_{n-1}-\phi_{r} R_{n-1}\right]+\lambda_{u}\left[U_{n-1}+\alpha_{u} U_{n-1}-\phi_{u} U_{n-1}\right] \\
& U_{n}=U_{n-1}+\alpha_{u} U_{n-1}-\phi_{u} U_{n-1}-\lambda_{u}\left[U_{n-1}+\alpha_{u} U_{n-1}-\phi_{u} U_{n-1}\right]+\lambda_{r}\left[R_{n-1}+\alpha_{r} R_{n-1}-\phi_{r} R_{n-1}\right]
\end{aligned}
$$

That is:

$$
R_{n}=\left[1+\left(1-\lambda_{r}\right)\left(\alpha_{r}-\phi_{r}\right)-\lambda_{r}\right] R_{n-1}+\lambda_{u}\left[1+\alpha_{u}-\phi_{u}\right] U_{n-1}
$$

and

$$
U_{n}=\left[1+\left(1-\lambda_{u}\right)\left(\alpha_{u}-\phi_{u}\right)-\lambda_{u}\right] U_{n-1}+\lambda_{r}\left[1+\alpha_{r}-\phi_{r}\right] R_{n-1}
$$

Figure 1 illustrates the migration of the populations from rural $(R)$ and urban $(U)$ areas in Ghana.

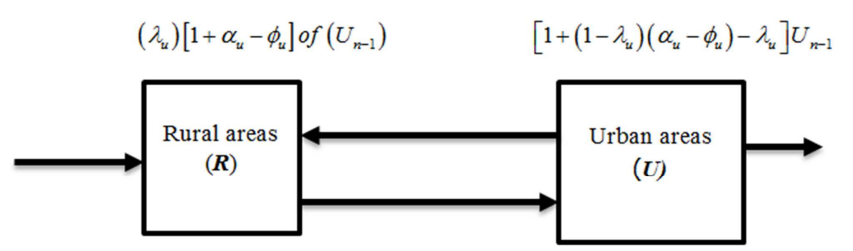

$$
\left[1+\left(1-\lambda_{r}\right)\left(\alpha_{r}-\phi_{r}\right)-\lambda_{r}\right] R_{n-1} \quad\left(\lambda_{r}\right)\left[1+\alpha_{r}-\phi_{r}\right] \text { of }\left(R_{n-1}\right)
$$

Figure 1. Migration dynamics of Rural and Urban Areas in Ghana.

\subsection{Matrix Formation}

If $U$ represent the urban population and $R$ represent the rural population of Ghana, then the population vector for rural and urban population is given as:

$$
\left(\begin{array}{c}
\text { Rural } \\
\text { Urban }
\end{array}\right)=\left(\begin{array}{c}
R \\
U
\end{array}\right)
$$

Since the urban and rural populations of Ghana in 2015 were respectively, $14,812,854$ and $12,597,039$ their population vector is represented by:

$$
\left(\begin{array}{l}
R_{2015} \\
U_{2015}
\end{array}\right)=\left(\begin{array}{l}
12,597,039 \\
14,812,854
\end{array}\right)
$$

Also if $n=1$ represents the year 2016, then ( $n-1)$ will be its previous year, that is 2015. From Equation (4) the rural 
population size at $n^{\text {th }}$ year is represented as:

$$
R_{n}=\left[1+\left(1-\lambda_{r}\right)\left(\alpha_{r}-\phi_{r}\right)-\lambda_{r}\right] R_{n-1}+\lambda_{u}\left[1+\alpha_{u}-\phi_{u}\right] U_{n-1}
$$

Similarly, from Equation (5) the population size at the urban area in the $n^{\text {th }}$ year is (I have respectively checked Equations (10) to (12) and they are correct. Find the explanation on attached page)

$$
U_{n}=\left[1+\left(1-\lambda_{u}\right)\left(\alpha_{u}-\phi_{u}\right)-\lambda_{u}\right] U_{n-1}+\lambda_{r}\left[1+\alpha_{r}-\phi_{r}\right] R_{n-1}
$$

Combining Equation (8) and (9) yields Equation (10) which denotes the system of two consistent equations for the rural and urban populations in the $n^{\text {th }}$ year

$$
\left.\begin{array}{l}
R_{n}=\left[1+\left(1-\lambda_{r}\right)\left(\alpha_{r}-\phi_{r}\right)-\lambda_{r}\right] R_{n-1}+\lambda_{u}\left[1+\alpha_{u}-\phi_{u}\right] U_{n-1} \\
U_{n}=\left[1+\left(1-\lambda_{u}\right)\left(\alpha_{u}-\phi_{u}\right)-\lambda_{u}\right] U_{n-1}+\lambda_{r}\left[1+\alpha_{r}-\phi_{r}\right] R_{n-1}
\end{array}\right\}
$$

Equations (10) in matrix form becomes

$$
\left(\begin{array}{c}
R_{n} \\
U_{n}
\end{array}\right)=\left(\begin{array}{cc}
{\left[1+\left(1-\lambda_{r}\right)\left(\alpha_{r}-\phi_{r}\right)-\lambda_{r}\right]} & \lambda_{u}\left[1+\alpha_{u}-\phi_{u}\right] \\
\lambda_{r}\left[1+\alpha_{r}-\phi_{r}\right] & {\left[1+\left(1-\lambda_{u}\right)\left(\alpha_{u}-\phi_{u}\right)-\lambda_{u}\right]}
\end{array}\right)\left(\begin{array}{c}
R_{n-1} \\
U_{n-1}
\end{array}\right)
$$

Substituting $\mathrm{n}=1$ for 2016 in Equation (10), we obtained Equation (12) shown below:

$$
\left(\begin{array}{l}
R_{1} \\
U_{1}
\end{array}\right)=\left(\begin{array}{cc}
{\left[1+\left(1-\lambda_{r}\right)\left(\alpha_{r}-\phi_{r}\right)-\lambda_{r}\right]} & \lambda_{u}\left[1+\alpha_{u}-\phi_{u}\right] \\
\lambda_{r}\left[1+\alpha_{r}-\phi_{r}\right] & {\left[1+\left(1-\lambda_{u}\right)\left(\alpha_{u}-\phi_{u}\right)-\lambda_{u}\right]}
\end{array}\right)\left(\begin{array}{l}
R_{0} \\
U_{0}
\end{array}\right)
$$

Where $\left(\begin{array}{l}R_{2015} \\ u_{2015}\end{array}\right)=\left(\begin{array}{l}R_{0} \\ U_{0}\end{array}\right)=\left(\begin{array}{l}12,597,037 \\ 14,812,854\end{array}\right)$ and $\left(\begin{array}{l}R_{1} \\ U_{1}\end{array}\right)=\left(\begin{array}{l}R_{2016} \\ U_{2016}\end{array}\right)$

$$
\left.\left(\begin{array}{l}
R_{1} \\
U_{1}
\end{array}\right)=\left(\begin{array}{cc}
{\left[1+\left(1-\lambda_{r}\right)\left(\alpha_{r}-\phi_{r}\right)-\lambda_{r}\right]} & \lambda_{u}\left[1+\alpha_{u}-\phi_{u}\right] \\
\lambda_{r}\left[1+\alpha_{r}-\phi_{r}\right] & {\left[1+\left(1-\lambda_{u}\right)\left(\alpha_{u}-\phi_{u}\right)-\lambda_{u}\right.}
\end{array}\right]\right)\left(\begin{array}{l}
12,597,037 \\
14,812,854
\end{array}\right)
$$

Similarly for 2017 with $n=2$, Equation (10) provides its matrix system as:

$$
\left(\begin{array}{c}
R_{2} \\
U_{2}
\end{array}\right)=\left(\begin{array}{cc}
{\left[1+\left(1-\lambda_{r}\right)\left(\alpha_{r}-\phi_{r}\right)-\lambda_{r}\right]} & \lambda_{u}\left[1+\alpha_{u}-\phi_{u}\right] \\
\lambda_{r}\left[1+\alpha_{r}-\phi_{r}\right] & {\left[1+\left(1-\lambda_{u}\right)\left(\alpha_{u}-\phi_{u}\right)-\lambda_{u}\right.}
\end{array}\right)\left(\begin{array}{c}
R_{1} \\
U_{1}
\end{array}\right)
$$

That is:

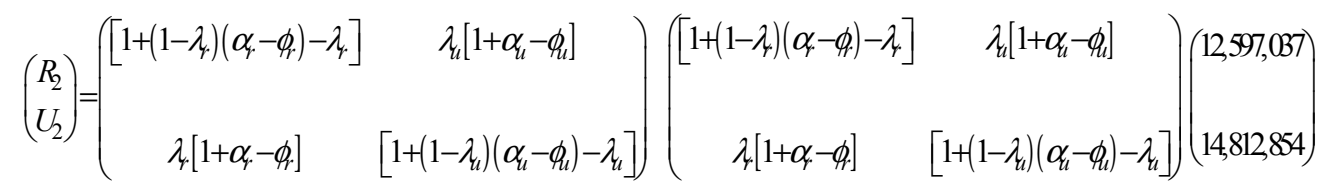

From Equations (12) and (13), we have the difference equation shown at Equation (14)

$$
P_{n}=A^{n} P_{0}
$$

where $P_{0}$ is the initial (2015) population, $P_{n}$ the rural and urban population values in the nth year and $A$ the transformation occurring in the population for all $n \geq 1$.

\section{Assumptions}

The intention of the paper is to take a fairly new approach 
to study migration trends by considering the following four assumptions that appeared to fit it. These are described below $[7,8]$ :

1) $3 \%$ of rural population move to the urban areas and $1 \%$ of urban population move to the rural areas per year

2) $1.4 \%$ and $1.7 \%$ births are recorded at the rural and urban areas per year

3) $0.3 \%$ and $0.4 \%$ deaths are recorded at rural and urban areas per year

4) the initial rural and urban population values in 2015 are $12,597,037$ and $14,812,854$

$$
\left(\begin{array}{c}
R_{1} \\
U_{1}
\end{array}\right)=\left(\begin{array}{cc}
{\left[1+\left(1-\lambda_{r}\right)\left(\alpha_{r}-\phi_{r}\right)-\lambda_{r}\right]} & \lambda_{u}\left[1+\alpha_{u}-\phi_{u}\right] \\
\lambda_{r}\left[1+\alpha_{r}-\phi_{r}\right] & {\left[1+\left(1-\lambda_{u}\right)\left(\alpha_{u}-\phi_{u}\right)-\lambda_{u}\right]}
\end{array}\right)\left(\begin{array}{l}
12,597,037 \\
14,812,854
\end{array}\right)
$$

which is transformed into Equation (15) with the inputs from the assumptions:

$$
\left(\begin{array}{l}
R_{1} \\
U_{1}
\end{array}\right)=\left(\begin{array}{cc}
{[1+(0.97)(0.011)-0.03]} & 0.01[1.013] \\
0.03[1.011] & {[1+(0.99)(0.013)-0.01]}
\end{array}\right)\left(\begin{array}{c}
12,597,037 \\
14,812,854
\end{array}\right)
$$

Thus, $\left(\begin{array}{l}R_{1} \\ U_{1}\end{array}\right)=\left(\begin{array}{ll}0.981 & 0.010 \\ 0.030 & 1.003\end{array}\right)\left(\begin{array}{l}12,597,037 \\ 14,812,854\end{array}\right)$

which represents the estimates for 2016 rural and urban populations. That is:

$$
\left(\begin{array}{l}
R_{1} \\
U_{1}
\end{array}\right)=\left(\begin{array}{l}
12,505,822 \\
15,235,204
\end{array}\right)
$$

Using the same matrix method, the estimated populations for the rural and urban areas in Ghana from 2016 to 2020 are provided in Table 2 .

Table 2. Estimated rural and urban populations in Ghana from 2016-2020.

\begin{tabular}{llllll}
\hline Year & Rural Population (R) & Urban Population (U) & Total Ghana's Population & $\begin{array}{l}\text { Percentage (\%) of Rural } \\
\text { Population }\end{array}$ & $\begin{array}{l}\text { Percentage (\%) of Urban } \\
\text { Population }\end{array}$ \\
2016 & $12,505,822$ & $15,235,204$ & $27,741,026$ & 45.08 \\
2017 & $12,420,563$ & $15,656,084$ & $28,076,647$ & 44.24 \\
2018 & $12,341,133$ & $16,075,669$ & $28,416,802$ & 43.43 \\
2019 & $12,267,408$ & $16,494,130$ & $28,76,1538$ & 42.65 \\
2020 & $12,199,269$ & $16,911,634$ & $29,110,903$ & 41.91 \\
\hline
\end{tabular}

\section{Discussion}

The clustered column chart in Figure 2 and the graph matrix in Figure 3 which examined the rural-urban population values for the period 2016-2020 show clearly the downward and upward trends of the rural and urban populations. Table 2 shows both the percentage values and the actual numeric results of the rural and urban populations, while the clustered column chart and the graph of matrix at Figures 2 and 3 respectively provide visual summary of the variation of the trends. The downwards trend of rural population may be due to many reasons, some of which include the massive movement of people from the rural to urban area in search of decent living. The extent of effects in the rural area is what this study seeks to draw the government attention to.

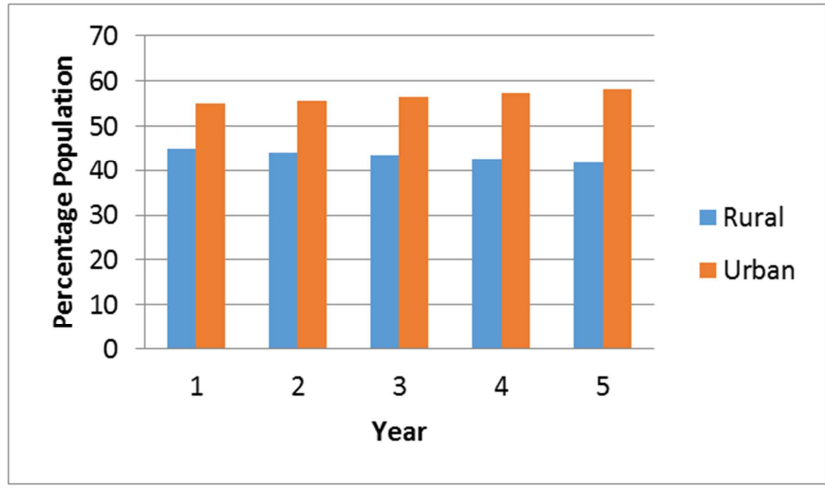

Figure 2. Clustered column chart of percentage values of rural and urban populations in Ghana from 2016-2020. 


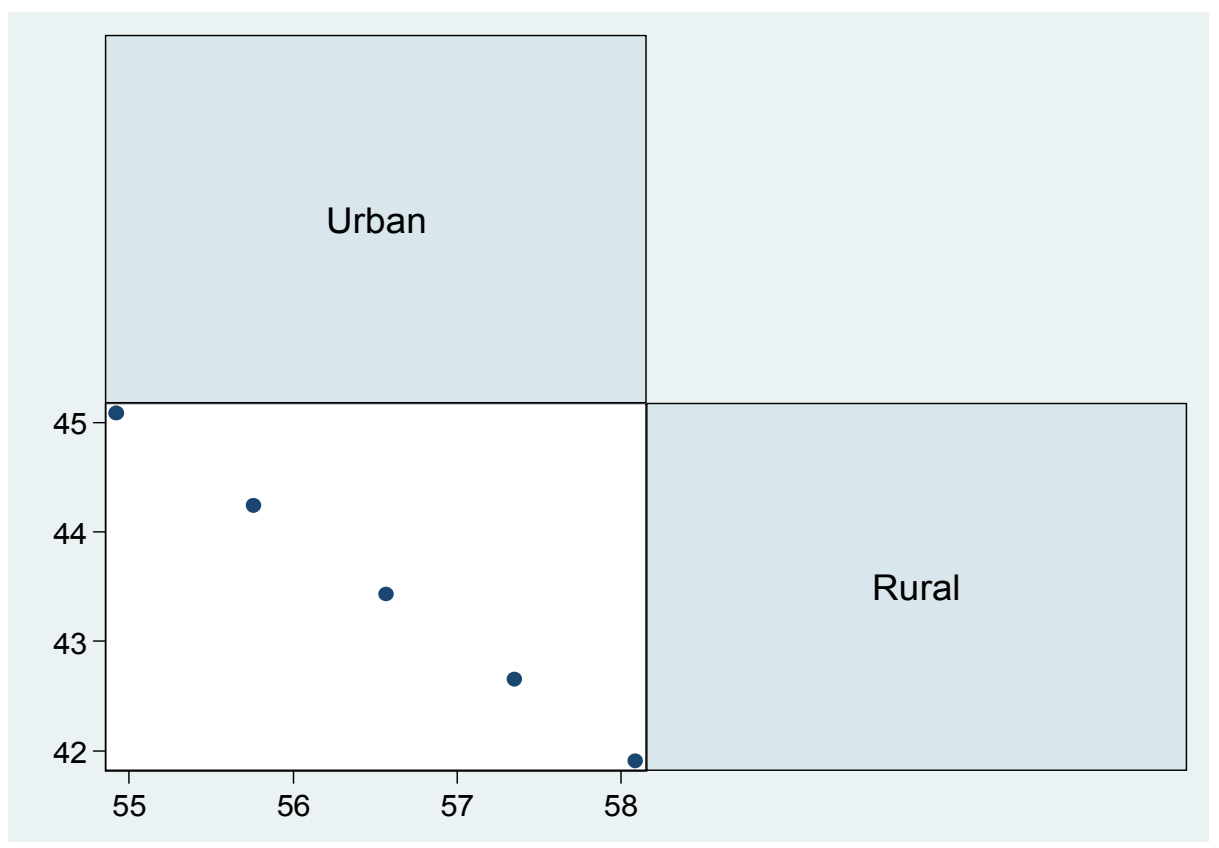

Figure 3. Graph of matrix of percentage values of rural and urban populations.

\subsection{Validation of the Matrix Method}

Table 3. Estimated percentage population values of the matrix method for rural and urban populations.

\begin{tabular}{lllll}
\hline Year & $\begin{array}{l}\text { Actual \% population of Rural } \\
\text { area (R) }\end{array}$ & $\begin{array}{l}\text { Estimated \% population of } \\
\text { Rural area (R) }\end{array}$ & $\begin{array}{l}\text { Actual \% population of } \\
\text { Urban area (U) }\end{array}$ & $\begin{array}{l}\text { Estimated \% population of } \\
\text { Urban area (U) }\end{array}$ \\
\hline 2011 & 48.61 & 49.15 & 51.39 & 50.85 \\
2012 & 47.93 & 48.42 & 52.07 & 51.58 \\
2013 & 47.27 & 47.83 & 52.74 & 52.17 \\
2014 & 46.61 & 46.87 & 53.39 & 53.10 \\
2015 & 46.0 & 45.96 & 54.0 & 54.09 \\
\hline
\end{tabular}

Source: Index mundi, Ghana rural population.

Table 3 compares the estimated percentage values from the matrix method with the actual population percentage values from the index Mundi website. The results in Table 3 showed that the estimated values from the matrix method were almost equal to the values from the website of Index Mundi in the literature for most cases. Table 3 shows that the matrix method was accurate and appropriate since it provided values very close to the actual values or the reference values. The effectiveness of the matrix method is established; thereby making it a suitable technique for studying migration trends of rural-urban population.

\section{Conclusion}

In this paper we have introduced a method which is suitable for studying the migration trends of rural and urban populations. Though, the method still has some limitations which can be investigated, it is believed to be a novel approach of applying matrix method in rural - urban population migration trends. The decreasing and increasing trends in the population of rural and urban populations were demonstrated in Table 2, Figure 2 and 3 respectively. With the assumption considered in this paper, the matrix method estimated that by the year 2020 the urban population would hit 16,911,634 while rural population would also hit $12,199,269$ as Ghana's population continue to increase. Though this assumption can be violated in the real-world cases, the decreasing trend of rural population in Ghana is a source of worry and requires immediate action from the Government and other stake-holders. According to the population pyramid of the world, Ghana's population will hit 30.5 million by the year 2020 with about $58.9 \%$ of the population residing at the urban area. However, the matrix method estimated Ghana's population at 2020 as $29,110,903$ with about $58.1 \%$ of the population at the urban area and $41.1 \%$ at the rural area. The main objective of the paper was to look at the trend of rural population and estimate the population values of rural and urban areas for the year 2020 . The results presented in Table 2 indicate population trends in rural and urban areas in Ghana which make the method more understandable for those who are new to this approach. Validation to check the accuracy of the method was carried out and the result shown in Table 3 exhibited the effectiveness of the method. Clearly, the decreasing trend of 
population values of rural population was observed and needs urgent attention.

\section{Recommendations}

On the basis of these observations, the paper is of the view that increasing access to resources at the rural areas, creating favourable conditions for the people to utilize their skills and encouraging greater entrepreneurship at the rural areas should be of great concern to the Government and other stake-holders. Furthermore, improving the living standards of the rural people by providing jobs, decent housing, proper medical care and good education may avert migration onto urban areas and these interventions should not be left out in the Government's plans. Rural development and agriculture should be given high priority in government planning programmes in order to reduce migration. The Government must also establish proper agricultural storage facilities at the rural areas to store all purchased agricultural stuffs produced by farmers. When these steps are taken, the rural folks will develop interest in agriculture and continue to stay and work in the rural areas. Poverty alleviation programs should be converted into self- employment programs to enable people in the rural area to obtain gainful productive employment at their native place. The Government and other Policy makers in Ghana should strive to address the push factors of rural areas by ensuring fair share of the national cake so as to promote equal developments in both rural and urban areas. Though some studies had already been done in this area, more work needs to be done. It is believed that this work will further provide valuable ideas for other researchers and practitioners who are still working in this area.

\section{References}

[1] Adewale, R. J. G. (2005), "Socio-Economic Factors Associated with Urban-Rural Migration in Nigeria: A Case Study of Oyo State, Nigeria", Journal of Human Ecology, Vol. 17, No. 1, pp. 13-16.

[2] Aidoo, P. (2012), Economics Textbook for Senior High Schools in West Africa, Mar-keyn Publications, Ghana, 585pp.

[3] Aleshkovski, I. and Iontsev, V. (2016), “Mathematical Models of Migration", https://www.eolss.net/ebooklib/sc_cart.aspx?File =E1-26-0906. Accessed: October 9, 2017.
[4] Ali, H., Shafi M. M., Rehman, M. U., Jadoon, M. A. (2015), "Causes and Effects of Rural-Urban Migration in Rural Areas of Khyber Pakhtunkhwa-Pakistan", Arts and Social Sciences Journal, Vol. 6, pp. 1-6.

[5] Anon. (2017a), "Worldometers", www.worldometers.info/world-population/ghana-population/. Accessed: October 10, 2017.

[6] Anon. (2012b), "Ghana Statistical Service, 2010 Population and Housing Census Summary Report of Final Results", Accra, Ghana.

[7] Anon. (2017c), "Index Mundi, Ghana Rural Population", www.indexmundi.com/facts/Ghana/rural-population. Accessed: October 22, 2017.

[8] Anon. (2017b), "Index Mundi, Ghana Demographics Profile,"https://www.indexmundi.com/ghana/demographics_pr ofile.html. Accessed: October 22, 2017.

[9] Anon. (2010d), "Population Pyramid. net, Population of Ghana", https://www.populationpyramid.net/ghana/20020/

[10] Appianing, S. (2013), "Causes and Consequences of RuralUrban Migration on Children Left-behind by the Migrants: A Case Study of Ningo-Prampram District in the Greater Accra Region", Unpublished Master's Thesis, University of Ghana, Legon, 88pp.

[11] Asma, S. M. (2015), "Rural Urban Migration; Socio-Cultural Changes in Pakistan-Preventive Measures Taken by Government and Civil Society to Control it", The Professional Medical Journal, Vol. 22, No. 6, pp. 674-682.

[12] Aydiko, A. A. (2015), "The Cause and Consequences of Rural Urban Migration, Munich, GRIN Verlag", $\mathrm{http} / / /$ www.grin.com/en/e-book/307635/the-cause-andconsequences-of-rural-urban-migration. Accessed: October 10,2017

[13] Birhan, A. M. (2011), "Causes and Consequences of RuralUrban Migration: The Case of Woldiya Town, North Ethiopia", Unpublished Master's Thesis, University of South Africa, 115pp.

[14] Ravenstein, E. G. (1985), "The Law of Migration”, Journal of Royal Statistical Society, Vol. 48, No. 2, pp. 167-235.

[15] Wuni, B. M. (2013), "Perceived Impact of Rural-Urban Migration on Agricultural Productivity in Nanumba South District of Northern Region", Unpublished Master's Thesis, University of Ghana, Legon, 105pp. 